\title{
Determining the performance of website-based relationship marketing
}

Kerstin Schäfer, Tyge-F. Kummer

Keywords: Website performance evaluation, relationship marketing, clickstream data, online consumer behavior 


\begin{abstract}
Company websites are an important instrument for relationship marketing activities. We present a methodological framework that aligns website performance assessment and marketing intelligence for evaluating the performance of relationship marketing activities. In this context, we develop an extended web mining approach that integrates managerial perspectives in the analyst's investigation of the customer-website interaction based on historical clickstream data.

This approach enables quantification of the moderating effect of a website's structure and content regarding website-based relationship marketing. The applicability of our approach is demonstrated by clickstream data of 477,471 visitor sessions on a software developer's website. The results provide detailed insights into the usage behavior on a website and the mechanisms to enhance e-commerce efficiency via website optimization.
\end{abstract}




\section{Introduction}

Today's companies use their websites as windows through which much of the world will see it (Winter, Saunders, \& Hart, 2003). In contrast to traditional e-commerce sites or portals, modern corporate websites provide a broad range of information about themselves, their products and related services to the public (Stuart $\&$ Jones, 2004). As a result, the online presence becomes the most important communication channel a company possesses; determining how effective it supports this communication function is crucial in the overall webpage evaluation (Weinberg, Parise, \& Guinan, 2007).

Several approaches have been introduced to improve web performance covering models based on web mining and click stream analysis (Cho, Kim, \& Kim, 2002; Chou, Li, Chen, \& Wua, 2010; Kalczynski, Senecal, \& Nantel, 2006; Kim \& Yum, 2011), web-based marketing (Tsai, Chou, \& Leu, 2011; Wang, Wang, \& Farn, 2009) as well as online effectiveness and website evaluation (Chou \& Cheng, 2012; Kim, Kwon, \& Chang, 2011). Due to its practical importance, this issue is for example also addressed by popular evaluation instruments such as the Web Effectiveness Index, which helps investigating how a corporate website reacts on global communication trends and how it performs against its peers by quantifying the serving potential for different public target groups (BowenCraggs \& Co, 2011). Although such performance indicators are beneficial for companies, they often exclude direct business related measurements, because they cannot quantify website performance in their serving character for the customer value (Financial Times/Bowen Craggs \& Co, 2011). But this is of utmost importance, as besides benchmarking among peers, companies need to assess customer value first for achieving a competitive advantage (Woodruff, 1997).

Business relevant measures can be included by referring to the company’s applied relationship marketing strategies (RMS), which aim at establishing, developing, and maintaining successful relational exchanges with its customers (Morgan \& Hunt, 1994). These strategies are directly reflected in online performance, as the Internet also became the most important communication channel for a company’s RM effort (Srinivasan \& Moorman, 2005). The evaluation of such RM effectiveness is based on customer behavior and allows increasing a company's return of RM investment by offering demand-actuated strategies and services (Reinartz \& Kumar, 2003). In this line of arguing, customer value can be determined in two steps: firstly, by measuring how well the corporate website moderates the company RMS, which is expressed in how well it serves its customers online; and secondly, by inferring involved relationship economics (Palmatier, Dant, Grwal, \& Evans, 2006). As a result, the evaluation of corporate online performance can be integrated with internal business measures and is substantial for marketing decisions (Weischedel, Matear, \& Deans, 2005). 
Similar to the spread of relationship marketing evaluation that mainly uses customer data, website performance assessment increasingly takes place on the customer/visitor-level, empirically using clickstream data (Ayanso \& Yoogalingam, 2009; Hahn \& Kauffman, 2004; Kalczynski, et al., 2006; Olbrich \& Holsing, 2011/12). From the viewpoint of business practice, particularly the "easy-to-use" web analytic approaches that use internal web page-tagging, have been widely employed as they provide a fast method for surveying visitor behavior (Kohavi, Rothleder, \& Simoudis, 2002). However, their scope of analysis is usually limited to a structural, aggregated level of internal page frequentation and related web metrics such as stickiness or prominent exit pages (Booth \& Jansen, 2009; Olbrich \& Holsing, Winter 2011-12), which are difficult to relate to customer value. Investigating whole visitor paths using clickstream data can set a much broader scope; further, this allows to infer business relevant website performance measures from visitor usage behavior, as specified in various web mining approaches (Lee, Podlaseck, Schonberg, \& Hoch, 2001). Nevertheless, such elaborate approaches are highly underutilized in business practice due to their increased complexity in data storage, data preparation and analysis in comparison to typical web metric-based methodologies (Sen, Dacin, \& Pattichis, 2006).

However, only an investigation on website performance based on the individual visitor session level enables a valid demand-actuated evaluation of customer/visitor value by quantifying the effectiveness of a company's RM effort in their website usage. Though, suitable methodological approaches that are able to enrich existing company data by providing internal measure of website performance in the context of relational marketing analysis are rare (Hahn \& Kauffman, 2004; Hochsztain, Millán, Pardo, Pena, \& Menasalvas, 2003).

Furthermore, as far as we know, approaches that directly link the evaluation of a company's RM effectiveness to website performance, empirically based on customer website usage, do not exist.

In this study we attempt to overcome this shortage by presenting a methodological framework that aligns marketing analysis with web mining approaches on the theoretical level. Therein, we develop a methodological approach that integrates managerial perspectives into the modeling and analyzing of a company's RM effectiveness in website performance based on customer website usage data. The knowledge gained supports customer value determination by quantifying RM effective website usage behavior and also enables a demandactuated website optimization and customization for different relational marketing strategies. Furthermore, we extend existing web mining approaches by integrating managerial perspectives on website usage. Addressing Internet based marketing communication environments finally enriches traditional marketing analysis approaches. 
The paper is structured as follows: in the next section (2) we outline the related research. In section 3, we describe the developed methodology in detail. The practical relevance of our approach will be demonstrated in section 4 by analyzing historical clickstream data of a corporate web site from the software development sector. Finally, we conclude our research contribution and the limitations of our approach in section 5.

\section{Related Research in Performance Assessment}

Corporate websites are an important channel for Internet based marketing communication in a company's multichannel marketing efforts (Weinberg, et al., 2007). They support three relational marketing strategies (RMS) in particular: (1) the building of brand equity, which is the sum of the intangible assets of the corporate brand that are supported by factors such as name awareness, perceived quality and customer loyalty (Aaker, 1993); (2) the creation and maintenance of relationships at reduced costs (Sheth \& Parvatiyar, 2000); and (3) the creation of customer satisfaction by delivering superior products and services (Gale, 1994). Success in any of these strategies leads to an increase in repeat purchases, insulation from price increases and improved responsiveness to marketing communication by customers. Thus, a corporate website can maximize the impact of a company's RM efforts (Argyriou, Kitchen, \& Melewar, 2006). The strength of this contribution depends on how well the website performs with respect to customer information needs. Therefore it is necessary to develop metrics that evaluate the effectiveness in relation to customer website usage of the RM effort in website performance.

For business orientated performance measurements, marketing analysis provides a rich set of methodologies, which have been adapted to the Internet context subsequently. Initially, business performance assessment was conceptualized as assessment of product and service quality (i.e. SERVQUAL: (Carman, 1990; Parasuraman, Zeithaml, \& Berry, 1988). In these studies, the general measurement model determines a gap (the deviation) between managerial expectations towards performance and the actual performance based on customer evaluation of products and services (Asubonteng, McCleary, \& Swan, 1996; Teas, 1993). In the context of RM, the effectiveness evaluation uses data intensive methodologies based on customer purchase behavior (Vercellis, 2009). In related research this is commonly discussed in the notion of relationship economics that includes metrics such as customer lifetime value, acquisition, retention and cross-selling (Büchner \& Mulvenna, 1998; Chi \& Tavella, 2008). Subsequent, in IS an adaption of these marketing approaches took place. Website performance is either measured in terms of single marketing outcomes such as web-customer satisfaction and loyalty (McKinney, Yoon, \& Zahedi, 2002), or by deploying so-called WEBQUAL studies that focus rather on quality assessment and benchmarking (Lee, Strong, Kahn, \& Wang, 2002). 
Additionally, other IS studies investigate website performance directly by inferring customer value of the customer-website interaction in methodological approaches similar to marketing intelligence (Senecal, Kalczynski, \& Nantel, 2005; Spiliopoulou \& Pohle, 2001). In these studies, different effectiveness metrics are deployed depending on the website type. For transaction-orientated e-commerce websites, performance is assessed in terms of revenue. Thus, metrics are used that relate the customer lifecycle to customer web usage such as reach, acquisition, conversion, click through and look-to-buy (Lee, Hoch, Podlasek, Schonberg, \& Gomory, 1999; Teltzrow \& Berendt, 2003). Investigating customer web site usage in terms of customer behavior on the other hand assesses the performance of information and service provision orientated websites. Here, the clickstream data is interpreted as implicit feedback for meeting customer information needs (Bucklin \& Sismeiro, 2003) and effectiveness can be determined by evaluating the degree or amount of this serving (Stolz, Viermetz, Neuneier, \& Skubacz, 2005).

\section{Towards a Methodology for RMS Effectiveness Evaluation}

\subsection{Relationship Marketing Website Typology}

Integrating relationship marketing strategies (RMS) with related research from website performance assessment, an allocation of typical RMS and related metrics is possible: According to the functions a corporate website possesses, different RMS are supported, and different effectiveness metrics need to be distinguished. Adjusting the typology of website functions and metrics suggested by (Booth \& Jansen, 2009) for corporate website functions, as displayed in table 1, we specify firstly that a commerce orientation focuses on getting customers who visit the site to purchase goods or services directly from the website. The building of brand equity is the most important RMS here, because it addresses customer loyalty in terms of repeated purchases and perceived product quality. Clickstream-based effectiveness metrics for commerce emphasize transactions such as purchase or downloads. Secondly, content and media provision focuses on drawing in visitors and immersing them within the site. The relationship between a company and its customers can be strengthened as a result. Clickstreambased RMS effectiveness metrics are in this case concerned with visitor engagement, for instance a high number of visit actions indicating browsing, and long session duration. Finally, the support and service function helps users to find specialized answers for specific problems. This increases customer satisfaction at reduced external support costs. RMS effectiveness depends largely upon the provision of the searched information with regard to the structure of the website; thus, low page depth is a useful indicator in clickstream data.

Table 1 Website functions, RMS and metrics (Booth \& Jansen, 2009) 


\begin{tabular}{lll}
\hline Website function & $\begin{array}{l}\text { Related relationship marketing } \\
\text { strategy }\end{array}$ & Focus of web metric \\
\hline Commerce & Brand equity & Conversion \\
Content/media & Relationship maintenance & Visit depth, engagement \\
Support/self service & Customer Satisfaction & Page depth, fact-finding \\
\hline
\end{tabular}

In the following, a general research framework is presented and operationalized that integrates RMS

effectiveness determination in a web mining approach for modeling, evaluating and predicting RMS effectiveness in corporate website performance.

\subsection{An Extended Web Mining Approach}

The allocation of relational marketing strategies (RMS) to website functions is necessary for developing an extended web mining approach that integrates managerial perspectives in the analyst's investigation of the customer-website interaction based on historical clickstream data. This integration is reflected in our three-phase approach that contains six single steps: in phase 1, the business expert provides domain knowledge for identifying and characterizing typical corporate RMS in different website areas and related visitor activities (step 1). This domain knowledge is necessary for modeling and validating visitor activities in the clickstream data set by an analyst using statistical procedures (step 2). In Phase 2, the business expert further weights his previously specified visitor activities according to their relevance for achieving RMS effectiveness website area specific (step 3). Subsequently, the analyst calculates overall RMS effectiveness values in the clickstream data set among the modeled visitor activities using these relevance weights (step 4). In phase 3, the analyst determines RMS effectiveness factors by initially measuring the relative contribution of the modeled visitor activities to overall RMS effectiveness and by finally calculating the gap between the business expert's expectations towards the relevance of an activity in reaching RMS effectiveness and its empirical contribution to overall RMS effectiveness (step 5). The gained insights are then used as managerial implications by the business experts and transferred into website optimization requirements (step 6). Figure 1 gives an overview of the evaluation procedure.

Fig. 1 Overview of developed methodology for RMS effectiveness evaluation 


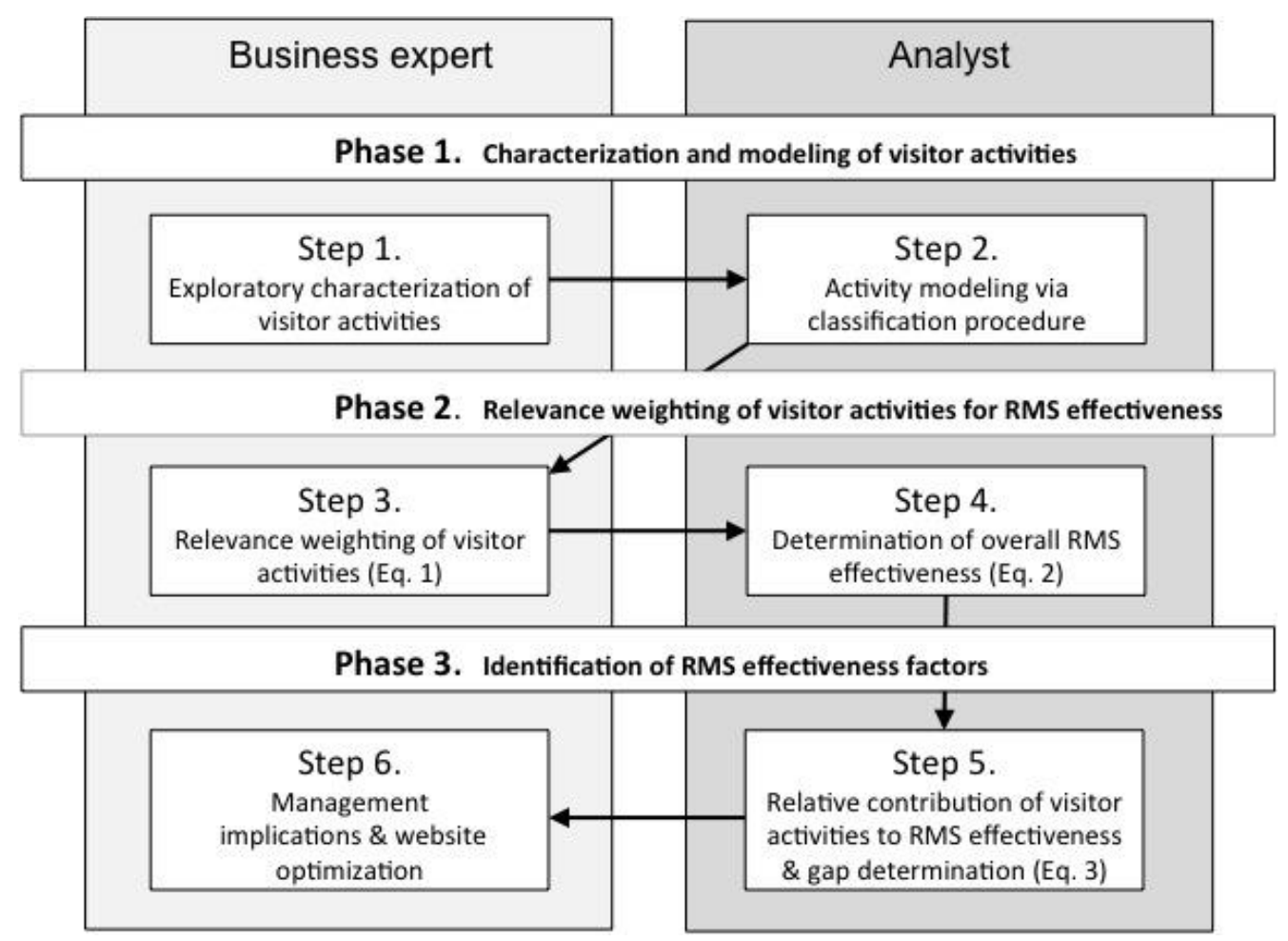

\section{Phase 1: Characterizing and modeling visitor activities}

Step 1. In an initial, exploratory approach a business expert provides the necessary corporate domain knowledge that guides the main analysis (Pyle, 1999). In it, he defines corporate RMS that are moderated by website performance and relates them to different website areas. For it, the expert manually explores the website structure and content and also uses an exploration data set (random sample of visitor sessions, $\mathrm{n} \approx 50$ ). This enables him to discriminate typical visitor activities which represent customer website interaction and to set thresholds of the used variables that are used in the clickstream analysis for each website area. Such typical activities are information gathering or browsing, fact-finding, and all possible transactions such as buying or downloading (Kellar, Watters, \& Shepherd, 2006). In clickstream data, browsing is usually characterized by a high number of clicks (visit actions) and a long session duration in a visitor session. Fact-finding, can be described by a low page depth, which implies a low number of visit actions and a certain style of interacting with the structural elements of the website content (Bucklin \& Sismeiro, 2003). Integrating a distinction of different page types, i.e. into action/navigational and target pages (Spiliopoulou \& Pohle, 2001), fact-finding is expressed by visiting only few navigational pages in order to find specific content on target pages.

Step 2. These insights are particularly relevant for the analyst, who uses this qualitative activity characterization for the specification of quantitative models and their validation in a training data set (random sample of visitor sessions from the historical clickstream, $\mathrm{n} \approx 5000$ ) With the help of these models, the analyst infers visitor 
activities from the historical clickstream data using statistical classification methods (decision tree) (Fox, Karnawat, Mydlands, Dumais, \& White, 2005). Therein, previously defined expert characterizations are used both for modeling of different visitor activities, as well as for identifying and selecting activity representing nodes in the decision tree. Comparing different models for each activity further ensures statistical validity.

\section{Phase 2: Relevance weighting of visitor activities for RMS effectiveness}

Step 3. Assuming that the corporate website supports different RMS, the initially characterized visitor activities are then weighted by the business experts according to their relevance for achieving RMS effectiveness in customer website usage. We express this formally: the strategy set $S=\left\{s_{1}, s_{2}, \ldots, s_{n}\right\}$ represents the current relational marketing strategies of a company that are moderated by the performance of its corporate website. The customer website usage set $U=\left\{u_{1}, u_{2}, \ldots, u_{m}\right\}$ represents different activities a visitor can engage in when interacting with the corporate website. Further, we define $w_{i j}$ as the weight to each relational marketing strategy, where $i$ represents the $i^{\text {th }}$ visitor activity and $j$ the $j^{\text {th }}$ relational marketing strategy. It is assumed that business experts assign weights differently for each visitor activity in every relational marketing strategy. The weight function $w_{i j}$ depends on $s_{i} \in S, u_{i} \in U$ and has the following properties:

$$
0 \quad \mathrm{w}_{i j} \quad 1 \quad \text { with }{ }_{i=1}^{n} w_{i j}=1
$$

For each RMS the sum of all visitor activities is always 1; when an activity possesses no weight, then it is not relevant for this RMS from a managerial point of view. Table 2 displays an example allocation of weighting properties, with “_“ indicating no relevance of an activity for this website area.

Table 2 RMS specific relevance weighting of visitor activities

\begin{tabular}{lccc}
\hline Visitor activity & Brand equity $\left(\mathrm{s}_{1}\right)$ & Relationship maintenance $\left(\mathrm{s}_{2}\right)$ & Customer satisfaction $\left(\mathrm{s}_{3}\right)$ \\
\hline Long stay/engagement $\left(\mathrm{u}_{1}\right)$ & - & $\mathrm{s}_{2} \mathrm{u}_{1}$ & - \\
$\begin{array}{l}\text { Information- } \\
\text { gathering/Browsing }\left(\mathrm{u}_{2}\right)\end{array}$ & - & $\mathrm{s}_{2} \mathrm{u}_{2}$ & - \\
Fact-finding $\left(\mathrm{u}_{3}\right)$ & & & $\mathrm{s}_{3} \mathrm{u}_{3}$ \\
Buy, download $\left(\mathrm{u}_{4}\right)$ & $\mathrm{s}_{1} \mathrm{u}_{3}$ & $\mathrm{~s}_{2} \mathrm{u}_{3}$ & $\mathrm{~s}_{3} \mathrm{u}_{4}$ \\
\hline
\end{tabular}


Step 4. This relevance weighting of visitor activities helps the analyst to determine overall RMS effectiveness in the clickstream data. For doing so, the analyst enriches the statistically identified and validated activities in the visitor sessions with the specified weights for each website area. Then, an effectiveness heuristic is applied for determining the amount of visitor sessions with RMS relevant customer website usage behavior in a website area, using a linear equation $L$ that specifies a dichotomous values: if the visitor session contains any RMS relevant activities, then the website successfully moderates a company's RM effort in this area; if the user session does not contain any RMS relevant activities, than the website fails to moderate the RM effort in this area. This is formally expressed by:

$$
L_{i}={ }_{j=1}^{m} s_{i} u_{j} .\left(\text { i.e. } L_{1}=s_{1} u_{1}+s_{1} u_{2}+\ldots+s_{1} u_{j}\right)
$$

- If $L_{i}>0$ then RMS effectiveness is determined in a visitor session,

- If $L_{i} \leq O$ than RMS failure is determined in a visitor session.

\section{Phase 3: RMS effectiveness contributing factors}

Step 5. Such a dichotomous overall RMS effectiveness value is further necessary for the last step of our evaluation procedure, where the analyst estimates the relative contribution of modeled visitor activities to overall RMS effectiveness website area specific using discriminant analysis. Further, by relating the actual contribution of a visitor activity to the specified relevance for achieving RMS effectiveness, the moderating effect of corporate website performance is quantified using gap analysis. Conceptually similar to Brown and Swartz's (Brown \& Swartz, 1989) gap determination procedure, we calculate a "RMS effectiveness contributionrelevance gap" calculated visitor activity wise for each website area and its attached RMS. In it, the relative

relevance values $w_{i j}$ with $s_{i} \in S, u_{i} \in U$ that are generated by business experts in step 3 (Eq. 1) are subtracted from the contribution activity values $c_{i j}$ with $s_{i} \in S, u_{i} \in U$ (see Eq. 2) that are estimated by discriminant analysis in step 5. The determination of gap values $G_{i j}$ is expressed:

$$
G_{i j}=c_{i j} \quad w_{i j}
$$

- If $G_{i j} \geq 0$ than the website supports the website moderation of the company's RM effort as reflected in customer website usage;

- If $G_{i j}<0$ than the website underperforms in moderating the companies RM effort. 
Step 6. These findings finally allow the analyst to formulate demand-actuated optimization recommendations that can increase RMS effectiveness of the corporate website and are used by the business expert for managerial decision-making.

\section{Example Implementation and Empirical Results}

The developed approach was applied for evaluating the effectiveness of the relational marketing strategies (RMS) in the website performance of a German software developer. The website is dynamic and contains over 25 billion distinct URLs for content generation. Further, the website possesses different functions that are reflected in distinct website areas such as commerce (shop), content and media provision (product catalogue, media center, company, community) and service and support (support). As specified by business experts, relevant RMS that are moderated by website performance are: (1) building of brand equity (shop area); (2) relationship maintenance (all content providing areas); and (3) creation and increase of customer satisfaction (support area).

\subsection{Clickstream Data Collection and Data Preparation}

For investigating RMS effectiveness in website performance, we collected server log files of the clickstream over a period of four weeks $(6.5 \mathrm{~GB})$. In the following data preparation and transformation process, according to (Cooley, Mobasher, \& Srivastava, 1999; Markov \& Larose, 2007), data was cleaned and sessionized using MySQL 5.5.9. In total, we identified and prepared 1,389,413 sessions with a session duration longer than 10 seconds and containing two or more visit actions for statistical analysis. For integrating structural information that allow distinguishing navigational and content page view objects, additional data was collected with a javabased agent: the crawler requested the HTML page title of each URL in the log files, which offers information about the website area and parsed them either as navigational or content objects. To this end, we deployed a decision heuristic: page view objects with more than 30 links are navigational; those with less than 30 links are content objects. This classification was successfully evaluated and validated by comparing the mean of session duration values (Spiliopoulou \& Pohle, 2001). In total, we identified 143546 distinct navigational, and 11075070 content objects in our data set.

For applying our developed web mining approach, we generated four data sets that allocate visitor sessions according to their clicks in a website area such as products, shop, community and support (multiple response possible). In further data quality monitoring, outliers were identified and removed using the interquartile range method (Larose, 2005) for the ratios of visit actions and session duration in each data set. Table 3 displays the 
average session ratio values that were used for model specification after outlier removal in the net samples (sum of net samples $=477,471$ sessions). These values also depict differences in customer website usage across website areas, which supports our website area specific evaluation approach.

Table 3 Average session ratio values in website areas

\begin{tabular}{lrrrr}
\hline Mean per website area & $\begin{array}{r}\text { Products } \\
(\mathrm{n}=114,264)\end{array}$ & $\begin{array}{r}\text { Shop } \\
(\mathrm{n}=158,529)\end{array}$ & $\begin{array}{r}\text { Community } \\
(\mathrm{n}=20,052)\end{array}$ & $\begin{array}{r}\text { Support } \\
(\mathrm{n}=184,626)\end{array}$ \\
\hline Session duration per website area $(S D)$ & 20.11 & 156.36 & 277.14 & 146.80 \\
$\begin{array}{l}\text { Session duration per navigational object } \\
\text { (SD_Nav) }\end{array}$ & 14.86 & 18.82 & 21.40 & 33.52 \\
$\begin{array}{l}\text { Session duration per content object } \\
\text { (SD_Con) }\end{array}$ & 5.25 & 137.55 & 255.74 & 113.28 \\
Visit actions in website area (VA) & & & 3.98 & 3.42 \\
Visit actions navigational objects (VA_Nav) & 2.85 & 3.85 & .56 & .80 \\
Visit actions content objects (VA_Con) & 2.06 & .79 & 3.26 & 3.41 \\
\hline
\end{tabular}

\subsection{Data Analysis and Results}

Statistical analysis was performed using PASW Statistics 18 and PASW Modeler 13. Data analysis proceeded according to the developed approach in three phases and six steps (figure 1). In step 1, the business expert executed a qualitative characterization and discrimination of RMS relevant visitor activities using the website and a provided exploration data set. As a result, thresholds for activity-modeling using the ratios visit actions $(V A)$ and session duration $(S D)$, and other values of the indicator variables that describe visitor activities were defined. In the subsequent classification procedure in step 2, a C\&RT regression tree was used for predicting the values of the visitor activities browsing and fact-finding, and for classifying visitor activities, first within a training data set and after successful validation in the whole data sets of the net samples. Measurement validity was ensured using the Gini-index as measure of impurity and a test-sample cross validation for tree-selection. The identification and selection of visitor activity representing nodes in the regression trees deployed the expert characterization. Then, two data models for each activity were created and compared, using one dependent (DV) and one or more independent variables (IV). For valid activity inference, the model with the lower standard error of the estimate $(s)$ was finally preferred. Then, an indicator variable was created in the visitor sessions for each inferred activity (Breiman, Friedman, Stone, \& Olshen, 1984). The regression models and the results of the model evaluation that prefers model 1, as well as the predicted values of the ratios in model 1 are shown in the 
Appendix (Table 8, 9). In the step 3, the business expert then weighted visitor activities according to their impact for achieving effective RMS in each investigated website area using Eq. 1, as presented in Table 4.

Table 4 Relevance weighting of visitor activities

\begin{tabular}{|c|c|c|c|c|c|}
\hline & Visitor activities & $\begin{array}{r}\text { Products } \\
\text { (Relationship } \\
\text { maintenance) }\end{array}$ & $\begin{array}{r}\text { Shop } \\
\text { (Building of } \\
\text { brand equity) }\end{array}$ & $\begin{array}{l}\text { Community } \\
\text { (Relationship } \\
\text { maintenance) }\end{array}$ & $\begin{array}{r}\text { Support } \\
\text { (Creation of } \\
\text { customer } \\
\text { satisfaction) }\end{array}$ \\
\hline \multirow{5}{*}{$\begin{array}{l}\text { Weights of } \\
\text { visitor } \\
\text { activities }\end{array}$} & Long stay & .5 & - & .5 & - \\
\hline & Browsing & .2 & - & .3 & - \\
\hline & Fact-finding & .2 & .1 & .1 & .9 \\
\hline & Download & .1 & .1 & .1 & .1 \\
\hline & Purchase & - & .8 & - & - \\
\hline Sum & & 1 & 1 & 1 & 1 \\
\hline
\end{tabular}

Subsequently, in step 4 overall RMS effectiveness was determined deploying the decision heuristic the Eq. 2

(Table 5). Results demonstrate that the company's RM effort is moderated differently in each website area: for relationship maintenance in the product area, only $45 \%$ of all visitor sessions were effective; whereas in the community area, which provides an exchange forum between customers, a high effectiveness of $77 \%$ in the visitor sessions was achieved. For the building of brand equity in the shop area, the website performed moderately efficient, with $48 \%$ of visitors sessions supporting RMS effectiveness. The creation of customer satisfaction displays the highest RMS failure, including $75 \%$ of all visitor sessions.

Table 5 Results of overall RMS effectiveness determination in visitor sessions

\begin{tabular}{|c|c|c|c|c|c|c|c|c|}
\hline & \multicolumn{2}{|c|}{$\begin{array}{l}\text { Products } \\
\text { (Relationship } \\
\text { maintenance) }\end{array}$} & \multicolumn{2}{|c|}{$\begin{array}{r}\text { Shop } \\
\text { (Building of brand } \\
\text { equity) }\end{array}$} & \multicolumn{2}{|c|}{$\begin{array}{l}\text { Community } \\
\text { (Relationship } \\
\text { maintenance) }\end{array}$} & \multicolumn{2}{|c|}{$\begin{array}{r}\text { Suppor } \\
\text { (Creation o } \\
\text { custome } \\
\text { satisfaction) }\end{array}$} \\
\hline & $\mathrm{N}$ & $\%$ & $\mathrm{~N}$ & $\%$ & $\mathrm{~N}$ & $\%$ & $\mathrm{~N}$ & $\%$ \\
\hline $\begin{array}{l}\text { RMS } \\
\text { effectiveness }\end{array}$ & 51,308 & 44.9 & 74,638 & 47.1 & 15,579 & 77.7 & 46,375 & 25.1 \\
\hline RMS failure & 62,956 & 55.1 & 83,891 & 52.9 & 4,473 & 22.3 & 138,251 & 74.9 \\
\hline Total & 114,264 & 100 & 158,529 & 100 & 20,052 & 100 & 184,626 & 100 \\
\hline
\end{tabular}

In step 5 of our evaluation, discriminant analysis was used for determining the relative contribution of the weighted activities to RMS effectiveness, which was also used as input for the following gap analysis procedure. For ensuring measurement validity of the discriminant function, the assumption of homogeneity of variance was 
fulfilled; analysis could thus be conducted. In model evaluation the quality of discrimination was very high, as shown in high eigenvalues and low values of Wilk's Lambda (eigenvalues between 5.04 and 8.84; Wilk's Lambda between .10 and .17 with $\mathrm{p}<.001)$. Further, classification results for the predicted group membership (RMS failure/effectiveness) are satisfying with $95.3 \%$ (products), 95.8 (community), 99\% (support), and 100\% (shop) for the correct prediction assumed a priori probability. Table 6 presents the average discriminant values and relative importance of the weighted visitor activities for RMS effectiveness.

Discriminant analysis results indicate that the relative contribution of website usage to RMS effectiveness varies across the website area and supports different visitor segments in customer value creation. For effective relationship maintenance, long stay is the greatest contributing factor in the products and community area.

Customer value can be gained by those visitors who browse in the product area and stay long in the community area because both activities indicate high visitor engagement with the website content and the company's products. Thus, the active and loyal customers from these activity segments are highly responsive to marketing communication. An effective building of brand equity in the shop area and effective creation of customer satisfaction in the support area are both determined by fact-finding as prominent activity. Thus, customer value is created by visitors who actively search for specific information and possess a structured interaction with the website structure and its content and therefore require less website external support.

Table 6 Discriminant analysis results

\begin{tabular}{|c|c|c|c|c|c|}
\hline & & $\begin{array}{l}\text { Products } \\
\text { (Relationship } \\
\text { maintenance) }\end{array}$ & $\begin{array}{r}\text { Shop } \\
\text { (Building of } \\
\text { brand equity) }\end{array}$ & $\begin{array}{l}\text { Community } \\
\text { (Relationship } \\
\text { maintenance) }\end{array}$ & $\begin{array}{r}\text { Support } \\
\text { (Creation of } \\
\text { customer } \\
\text { satisfaction) }\end{array}$ \\
\hline \multirow[t]{2}{*}{$\begin{array}{l}\text { Average } \\
\text { discriminant values }\end{array}$} & $\begin{array}{l}\text { RMS } \\
\text { effectiveness }\end{array}$ & -2.68 & -2.24 & -4.19 & -1.31 \\
\hline & RMS failure & 3.29 & 2.52 & 1.20 & 3.91 \\
\hline \multirow{5}{*}{$\begin{array}{l}\text { Standardized } \\
\text { discriminant } \\
\text { coefficients of } \\
\text { relevance weighted } \\
\text { activities for RMS } \\
\text { effectiveness }\end{array}$} & Long stay & .17 & & .88 & \\
\hline & Browsing & .65 & & .46 & \\
\hline & Fact-finding & .09 & .36 & .12 & .71 \\
\hline & Download & .11 & .08 & .09 & .15 \\
\hline & Purchase & & .30 & & \\
\hline
\end{tabular}

Integrating the companies understanding of visitor activity relevance and the empirical contribution of these activities to RMS effectiveness, we nevertheless identify a gap between both, as shown in Table 7. These gaps finally provide the basis of our website optimization recommendations, given to the business experts in step 6 of 
our evaluation approach. For an effective relationship maintenance three optimization factors occur that drastically influence customer value in terms of growing responsiveness to marketing communication, conversion and decrease of external support cost. First, long stay as indicator of high visitor engagement underperforms in the product area, although it is defined as an important effectiveness RMS effectiveness contribution factor. Second, also fact-finding underperforms in the product area, indicating difficulties accessing relevant content. Third, download provision also slightly underperforms in the community area. Hence, for increasing relationship maintenance in these areas, website optimization should engage in providing content that enables a higher visitor engagement and matches the visitors information needs, as well as structurally improving access to requested information and download libraries. With regard to an effective building of brand equity the website seriously underperforms in terms of all commerce related transactions in the shop.

Consequently, sales and downloads need to be increased by deploying transaction-enhancing mechanisms, usually referring to prices, discounts and other product characteristics. For an effective creation of customer satisfaction based on effective support and service provision, the website generally underperformances in terms of enabling the visitors' fact-finding activities. Optimization should engage here in structurally improving access to the searched information.

Table 7 Visitor activity contribution-relevance website performance gap

\begin{tabular}{llrrrr}
\hline & $\begin{array}{r}\text { Products } \\
\text { (Relationship } \\
\text { maintenance) }\end{array}$ & $\begin{array}{r}\text { Shop } \\
\text { (Building of } \\
\text { brand equity) }\end{array}$ & $\begin{array}{r}\text { Community } \\
\text { (Relationship } \\
\text { maintenance) }\end{array}$ & $\begin{array}{r}\text { Support } \\
\text { (Creation of } \\
\text { customer } \\
\text { satisfaction) }\end{array}$ \\
\hline $\begin{array}{l}\text { Performance gap in } \\
\text { visitor activities }\end{array}$ & Long stay & Browsing & -.33 & .38 \\
& Fact-finding & .45 & .26 & .16 \\
\\
Download & -.11 & -.02 & -.01 & -.19 \\
& & .1 & -.50 & .05 \\
\hline
\end{tabular}

\section{Conclusion and further research}

In this study we provide an effectiveness evaluation instrument for corporate websites that can be integrated with internal business measures and is substantial for marketing decisions. This approach overcomes the shortcomings of relationship marketing evaluations using clickstream data which are difficult to relate to customer value. Instead, our approach quantifies the effectiveness of a company's relationship marketing (RM) effort in its online performance empirically based on customer/visitor website usage. This allowed us further to 
determine customer value in two steps: firstly, by calculating the moderating degree of the corporate website for RM strategy effectiveness, which reflects the company's ability of serving customer information needs online; and secondly, by discussing involved relationship economics. Methodically, our evaluation approach aligns marketing analysis with web mining approaches. Results of our evaluation procedure support customer value determination and also enable a demand-actuated website optimization and customization for different relational marketing strategies.

The developed, marketing and IS research uniting methodology addresses both practitioners and researchers, as we developed a rigor methodological approach for website performance evaluation that is also highly applicable.

Our approach comprises six steps conducted in three phases by domain experts and analysts. Its clear structure enables guidance regarding the complex evaluation procedure by allocating tasks, and supporting communication between both stakeholder groups. We illustrated our approach by evaluating the website performance of a software developer. Here, we gave a detailed description of all involved methodological procedures including web data preparation, statistical analysis and effectiveness assessment. Finally, our results are used to derive managerial implications in order to improve company’s relationship marketing. For researchers, our findings can be used as a starting point regarding the determination of customer value in company’s RM. Additional case studies should be conducted to investigate the benefits of our approach. Furthermore, future applications based on this methodology could be developed supporting online analytical processing by providing visitor model development, identification and classification.

The main drawback of our developed method is the characterization and discrimination of visitor activities by a business expert, which impacts the quality and quantity of the activities modeled in the subsequent classification procedure. Further, the selection and weighting of RMS relevant visitor activities may not be adequate and exhaustive in a company's multi-channel marketing context. The extent of this problem can be limited by increasing external reliability. Here, inter-rater reliability could be enhanced by including several business experts in the qualitative procedures (step 1,3), which allows measuring the degree of agreement in their specifications, i.e. by using Cohen's kappa. Then, the inferential approach of modeling visitor behavior itself is limited and may not be representative for all customer segments, which differ in information needs and thus, usage behavior. Modeling and inferring customer segments prior to analysis could improve general results. Furthermore, the developed methodology has been applied on historical data only and needs to become extended, i.e. for integrating seasonal changes in website content, structure and possible changes in visitor behavior for enabling longitudinal evaluations of website performance. Eventually, the mentioned example only 
illustrates our approach. It does not enable an entire evaluation of our developed approach. This should be the aim of further publications in this domain.

\section{Acknowledgements}

Masked for review.

\section{Appendix}

Table 8 Data models for visitor activity "browsing"

\begin{tabular}{|c|c|c|c|c|}
\hline & & & Products & Community \\
\hline \multirow[t]{4}{*}{ C\&RT model 1} & Dependent & Visit actions & $>3.5$ & $>3.5$ \\
\hline & & $\begin{array}{l}\text { Session duration } \\
\text { navigational } \\
\text { objects }\end{array}$ & $<.5$ & $<.5$ \\
\hline & $\begin{array}{l}\text { Independent } \\
\text { variable }\end{array}$ & $\begin{array}{l}\text { Session duration } \\
\text { content objects }\end{array}$ & $>12.5$ & $>39.5$ \\
\hline & \multicolumn{2}{|c|}{ Model evaluation $s$} & .02 & .10 \\
\hline \multirow[t]{4}{*}{ C\&RT model 2} & $\begin{array}{l}\text { Dependent } \\
\text { variable }\end{array}$ & Session duration & $>15.5$ & $>32.5$ \\
\hline & \multirow[t]{2}{*}{$\begin{array}{l}\text { Independent } \\
\text { variable }\end{array}$} & $\begin{array}{l}\text { Visit actions } \\
\text { navigational } \\
\text { objects }\end{array}$ & $<1$ & $<1$ \\
\hline & & $\begin{array}{l}\text { Visit actions } \\
\text { content objects }\end{array}$ & $>2.5$ & $<4$ \\
\hline & \multicolumn{2}{|c|}{ Model evaluation $s$} & 4.34 & 1836.77 \\
\hline
\end{tabular}

Table 9 Data models for visitor activity "fact-finding"

\begin{tabular}{|c|c|c|c|c|c|c|}
\hline & & & Products & Shop & $\begin{array}{r}\text { Comm- } \\
\text { unity }\end{array}$ & Support \\
\hline \multirow[t]{4}{*}{$\begin{array}{l}\text { C\&RT } \\
\text { model } 1\end{array}$} & $\begin{array}{l}\text { Dependent } \\
\text { variable }\end{array}$ & Visit actions & $<3.5$ & $<3.5$ & $<3.5$ & $<3.5$ \\
\hline & & $\begin{array}{l}\text { Session duration } \\
\text { navigational } \\
\text { objects }\end{array}$ & $<.5$ & $<.5$ & $<.5$ & $<.5$ \\
\hline & $\begin{array}{l}\text { Independent } \\
\text { variable }\end{array}$ & $\begin{array}{l}\text { Session duration } \\
\text { content objects }\end{array}$ & $>2.5$ & $>39.5$ & $>31.5$ & $>14.5$ \\
\hline & \multicolumn{2}{|c|}{ Model evaluation $s$} & .01 & .03 & .10 & .02 \\
\hline \multirow[t]{2}{*}{$\begin{array}{l}\text { C\&RT } \\
\text { model } 2\end{array}$} & $\begin{array}{l}\text { Dependent } \\
\text { variable }\end{array}$ & Session duration & $<10$ & $<8$ & $<15$ & $<4$ \\
\hline & $\begin{array}{l}\text { Independent } \\
\text { variable }\end{array}$ & $\begin{array}{l}\text { Visit actions } \\
\text { navigational } \\
\text { objects }\end{array}$ & $<1$ & $<1$ & $<3$ & $<.5$ \\
\hline
\end{tabular}


Visit actions

content objects
$<5$

4.33
$<4$

167.44
$<3$

$<5.5$

\section{References List}

Aaker, D. (1993). Are brand equity investments really worthwhile? In D. A. Aaker \& A. Biel (Eds.), Brand equity and advertising: Advertising's role in building strong brands (pp. 333-341). Hillsdale, NJ: Erlbaum.

Argyriou, E., Kitchen, P. J., \& Melewar, T. C. (2006). The relationship between corporate websites and brand equity: A conceptual framework and research agenda. International Journal of Market Research, 48, 575-599.

Asubonteng, K., McCleary, K. J., \& Swan, J. E. (1996). SERVQUAL revisited: A critical review of service quality. The Journal of Services Marketing, 10, 62-81.

Ayanso, A., \& Yoogalingam, R. (2009). Profiling retail website functionalities and conversion rates: A cluster analysis. International Journal of Electronic Commerce, 14, 79-114.

Booth, D., \& Jansen, B. J. (2009). A review of methodologies for analyzing websites. In B. J. Jansen, A. Spink \& I. Taksa (Eds.), Handbook of research on web log analysis (pp. 141-163). Hershey, NY: IGI Global.

BowenCraggs \& Co. (2011). Index of corporate web effectiveness. In.

Breiman, L., Friedman, J., Stone, C. J., \& Olshen, R. (1984). Classification and regression trees. Wadsworth, Belmont: Chapman \& Hall.

Brown, S. W., \& Swartz, T. (1989). A gap analysis of professional service quality. Journal of Marketing, 53, 9298.

Büchner, A. G., \& Mulvenna, M. D. (1998). Discovering Internet marketing intelligence through online analytical web usage mining. SIGMOD Record, 27, 54-61.

Bucklin, R. E., \& Sismeiro, C. (2003). A model of web site browsing behavior estimated on clickstream data. Journal of Marketing Research, 40, 249-267.

Carman, J. M. (1990). Consumer perceptions of service quality: An assessment of the SERVQUAL dimensions. Journal of Retailing, 66, 33-55.

Chi, S., \& Tavella, D. (2008). Data mining and market intelligence for optimal marketing returns. Oxford, UK: Elsevier.

Cho, Y. H., Kim, J. K., \& Kim, S. H. (2002). A personalized recommender system based on web usage mining and decision tree induction. Expert Systems with Applications, 23, 329-342.

Chou, P.-H., Li, P.-H., Chen, K.-K., \& Wua, M.-J. (2010). Integrating web mining and neural network for personalized e-commerce automatic service. Expert Systems with Applications, 37 2898-2910.

Chou, W.-C., \& Cheng, Y.-P. (2012). A hybrid fuzzy MCDM approach for evaluating website quality of professional accounting firms. Expert Systems with Applications, 39, 2783-2793.

Cooley, R., Mobasher, B., \& Srivastava, J. (1999). Data preparation for mining world wide web browsing patterns. Journal of Knowledge and Information Systems, 1, 5-32.

Financial Times/Bowen Craggs \& Co. (2011). Financial Times Bowen Craggs Index 2011. In.

Fox, S., Karnawat, K., Mydlands, M., Dumais, S., \& White, T. (2005). Evaluating implicit measures to improve web search. ACM Transactions on Information Systems, 23, 147-168.

Gale, B. (1994). Managing Customer Value: Creating Quality and Service that Customers Can See. New York, NY: The Free Press.

Hahn, J., \& Kauffman, R. J. (2004). A methodology for business value-driven website evaluation: A data envelopment analysis approach. In Proceedings of the Third Annual Workshop on HCI Research in MIS (pp. 45-49). Washington, D.C.

Hochsztain, E., Millán, S., Pardo, B., Pena, J. M., \& Menasalvas, E. (2003). A framework to integrate business goals in web usage mining. In E. Menasalvas, J. Segovia \& P. S. Szczepaniak (Eds.), Advances in Web Intelligence: First International Atlantic Web Intelligence Conference (AWIC 2003) (pp. 28-45). Berlin, New York: Springer.

Kalczynski, P. J., Senecal, S., \& Nantel, J. (2006). Predicting On-Line Task Completion with Clickstream Complexity Measures: A Graph-Based Approach. International Journal of Electronic Commerce, 10, 121-141.

Kellar, M., Watters, C., \& Shepherd, M. (2006). A goal-based classification of web information tasks. Proceedings of the American Society for Information Science and Technology, 43, 1-22.

Kim, C., Kwon, K., \& Chang, W. (2011). How to measure the effectiveness of online advertising in online marketplaces. Expert Systems with Applications, 38 4234-4243.

Kim, Y. S., \& Yum, B.-J. (2011). Recommender system based on click stream data using association rule mining. Expert Systems with Applications, 38 13320-13327. 
Kohavi, R., Rothleder, N. J., \& Simoudis, E. (2002). Emerging trends in business analytics. Communications of the ACM, 45, 45-48.

Larose, D. T. (2005). Discovering knowledge in data: An introduction to data mining. New York, NY: Wiley.

Lee, J., Hoch, R., Podlasek, M., Schonberg, E., \& Gomory, S. (1999). Analysis and visualization of metrics for online merchandising, web usage analysis and user profiling. In Proceedings of the International WEBKDD'99 Workshop (pp. 126-141). San Diego, USA.

Lee, J., Podlaseck, M., Schonberg, E., \& Hoch, R. (2001). Visualization and Analysis of Clickstream Data of Online Stores for Understanding Web Merchandising. Data Mining and Knowledge Discovery, 5, 5984.

Lee, Y. W., Strong, D. M., Kahn, B. V., \& Wang, R. Y. (2002). AIMQ: a methodology for information quality assessment. Information and Management, 40, 133-146.

Markov, Z., \& Larose, D. T. (2007). Data mining the web: Uncovering patterns in web content, structure, and usage. New York, NY: Wiley.

McKinney, V., Yoon, K., \& Zahedi, F. M. (2002). The measurement of web-customer satisfaction: An expectation and disconfirmation approach. Information Systems Research, 13, 296-315.

Morgan, R. M., \& Hunt, S. D. (1994). The commitment-trust theory of relationship marketing. The Journal of Marketing, 58, 20-38.

Olbrich, R., \& Holsing, C. (Winter 2011-12). Modeling Consumer Purchasing Behavior in Social Shopping Communities with Clickstream Data. International Journal of Electronic Commerce, 16, 15-40.

Palmatier, R. W., Dant, R. P., Grwal, D., \& Evans, K. R. (2006). Factors influencing the effectiveness of relationship marketing: A meta-analysis. Journal of Marketing, 70, 136-153.

Parasuraman, A., Zeithaml, V., \& Berry, L. (1988). SERVQUAL: A Multiple-Item Scale for Measuring Consumer Perceptions of Service Quality. Journal of Retailing, 64, 12-40.

Pyle, D. (1999). Data preparation for data mining (3rd ed.). San Francisco: Morgan Kaufmann.

Reinartz, W. J., \& Kumar, V. (2003). The impact of customer relationship characteristics on profitable lifetime duration. Journal of Marketing, 67, 77-99.

Sen, A., Dacin, P. A., \& Pattichis, C. (2006). Current trends in web data analytics. Communications of the ACM, 49, 85-91.

Senecal, S., Kalczynski, P. W., \& Nantel, J. (2005). Consumer's decision-making process and their online shopping behavior: A clickstream analysis. Journal of Business Research, 58, 1599-1608.

Sheth, J., \& Parvatiyar, A. (2000). Relationship marketing in consumer markets: Antecedents and consequences. In J. Sheth \& A. Parvatiyar (Eds.), Handbook of Relationship Marketing. Thousand Oaks, CA: Sage.

Spiliopoulou, M., \& Pohle, C. (2001). Data mining for measuring and improving the success of web sites. Data Mining and Knowledge Discovery, 5, 85-114.

Srinivasan, R., \& Moorman, C. (2005). Strategic firm commitments and rewards for customer relationship management in online retailing. Journal of Marketing, 69, 193-200.

Stolz, C., Viermetz, M., Neuneier, R., \& Skubacz, M. (2005). Web performance indicator by implicit user feedback - applications and formal approach. In Proceedings of the sixth International Conference of Web Information Systems Engineering (WISE 2005) (pp. 689-700). New York, NY.

Stuart, H., \& Jones, C. (2004). Corporate branding in marketspace. Corporate Reputation Review, 7, 84-93.

Teas, R. K. (1993). Expectations, performance evaluation, and consumer's perception of quality. The Journal of Marketing, 57, 18-34.

Teltzrow, M., \& Berendt, B. (2003). Web-usage-based success metrics for multi-channel businesses. In Proceedings of the ninth ACM SIGKDD International Conference on Knowledge Discovery and Data Mining (WEBKDD Workshop on Web Mining 2003) (pp. 17-27). Washington, D.C.

Tsai, W.-H., Chou, W.-C., \& Leu, J.-D. (2011). An effectiveness evaluation model for the web-based marketing of the airline industry. Expert Systems with Applications, 38, 15499-15516.

Vercellis, C. (2009). Business intelligence: Data mining and optimization for decision making. New York, NY: Wiley.

Wang, K., Wang, E. T. G., \& Farn, C.-K. (2009). Influence of Web Advertising Strategies, Consumer GoalDirectedness, and Consumer Involvement on Web Advertising Effectiveness. International Journal of Electronic Commerce, 13, 67-95.

Weinberg, B. D., Parise, S., \& Guinan, P. J. (2007). Multichannel marketing: Mindset and program development. Business Horizons, 50, 385-394.

Weischedel, B., Matear, S., \& Deans, K. R. (2005). The use of emetrics in strategic marketing decisions: A preliminary investigation. Journal of Internet Marketing and Advertising, 2, 109-125.

Winter, S. J., Saunders, C., \& Hart, P. (2003). Electronic window dressing: Impression management with websites. European Journal of Information Systems, 12, 309-322.

Woodruff, R. B. (1997). Customer value: The next source for competitive advantage. Journal of the Academy of Marketing Science, 25, 139-153. 